\title{
Wait times to rheumatology care for patients with rheumatic diseases: a data linkage study of primary care electronic medical records and administrative data
}

\author{
Jessica Widdifield PhD, Sasha Bernatsky MD PhD, J. Carter Thorne MD, Claire Bombardier MD, \\ R. Liisa Jaakkimainen MD MSc, Laura Wing BMath, J. Michael Paterson MSc, Noah Ivers MD PhD, \\ Debra Butt MD MSc, Anne Lyddiatt, Catherine Hofstetter, Vandana Ahluwalia MD, Karen Tu MD MSc
}

\section{Abstract}

Background: The Wait Time Alliance recently established wait time benchmarks for rheumatology consultations in Canada. Our aim was to quantify wait times to primary and rheumatology care for patients with rheumatic diseases.

Methods: We identified patients from primary care practices in the Electronic Medical Record Administrative data Linked Database who had referrals to Ontario rheumatologists over the period 2000-2013. To assess the full care pathway, we identified dates of symptom onset, presentation in primary care and referral from electronic medical records. Dates of rheumatologist consultations were obtained by linking with physician service claims. We determined the duration of each phase of the care pathway (symptom onset to primary care encounter, primary care encounter to referral, and referral to rheumatologist consultation) and compared them with established benchmarks.

Results: Among 2430 referrals from 168 family physicians, 2015 patients (82.9\%) were seen by 146 rheumatologists within 1 year of referral. Of the 2430 referrals, 2417 (99.5\%) occurred between 2005 and 2013 . The main reasons for referral were osteoarthritis (32.4\%) and systemic inflammatory rheumatic diseases $(30.6 \%)$. Wait times varied by diagnosis and geographic region. Overall, the median wait time from referral to rheumatologist consultation was 74 (interquartile range 27-101) days; it was 66 (interquartile range 18-84) days for systemic inflammatory rheumatic diseases. Wait time benchmarks were not achieved, even for the most urgent types of referral. For systemic inflammatory rheumatic diseases, most of the delays occurred before referral.

Interpretation: Rheumatology wait times exceeded established benchmarks. Targeted efforts are needed to promote more timely access to both primary and rheumatology care. Routine linkage of electronic medical records with administrative data may help fill important gaps in knowledge about waits to primary and specialty care.

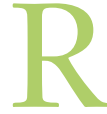
heumatic diseases represent the second-greatest cause of disability and have the fourth-greatest impact on overall world population health in terms of both death and disability. ${ }^{1,2}$ Optimal care for many rheumatic diseases hinges on early access to rheumatologists, but there are many hurdles that can impede optimal care, such as delays in patient presentation and physician referrals. ${ }^{3}$ Given the growing burden and overall impact of rheumatic diseases, ${ }^{4-6}$ providing patients with timely access to health care remains a panCanadian challenge that will only intensify over time.

The Wait Time Alliance recently released consensus-based rheumatology wait time benchmarks for inflammatory arthritis. The benchmarks were developed and endorsed by the Canadian
Rheumatology Association and Arthritis Alliance of Canada. ${ }^{7-9}$ Because the evidence for the benefits of early detection and treatment in improving patient outcomes has been best demonstrated in inflammatory arthritis, ${ }^{10-23}$ benchmarks for all types of rheumatic disease have not yet been established (Box 1). ${ }^{7}$

Competing interests: See the end of the article.

This article has been peer reviewed.

Correspondence to: Jessica Widdifield, Jessica.widdifield@ utoronto.ca CMAJ Open 2016. DOI:10.9778/cmajo.20150116 
Box 1: Wait time benchmarks: recommended maximum wait time from referral to rheumatologist consultation ${ }^{7,8}$

- Rheumatoid arthritis, other forms of inflammatory arthritis: 4 weeks

- Psoriatic arthritis: 6 weeks

- Spondyloarthritis: 3 months

- Systemic lupus erythematosus: 4 weeks

Unfortunately, there is no universal approach in Canada to systematically measure and monitor wait times from primary care referral to rheumatologist consultation. Reports on rheumatology wait times have arisen primarily from urban centres, which do not reflect the geographic realities of Canada. ${ }^{24-26}$ Also, previous studies quantifying delays to rheumatology care have focused predominantly on patients with rheumatoid arthritis from rheumatology clinics and thus restricted analyses to a subset of rheumatology referrals and patients who successfully accessed specialists. ${ }^{24,27-29}$ In light of this evidence gap, we used a novel approach to linking primary care electronic medical records (EMRs) with administrative health data to quantify delays to rheumatology care in Ontario. We evaluated wait times overall, for different diagnostic categories, for each component of the care pathway (from symptom onset to primary care physician encounter, from primary care encounter to referral request, and from referral to rheumatologist consultation) and by geographic region.

\section{Methods}

\section{Study design}

We conducted an observational study involving EMRs from Ontario primary care physicians (to provide accurate dates of referral requests) linked with health administrative data (to provide accurate dates of encounters with rheumatologists) over the period 2000-2013.

\section{Data sources}

We used the Electronic Medical Record Administrative data Linked Database, which comprises electronic clinical practice data from primary care physicians throughout Ontario. ${ }^{30}$ Information includes patient and provider demographic characteristics and all electronic data captured during primary care visits, current and past medical histories, laboratory test results, prescriptions, referral letters and diagnostic tests as well as information related to care received elsewhere and reported to the practice.

Data for participants in the Electronic Medical Record Administrative data Linked Database are linked to the following administrative datasets. The Ontario Health Insurance Plan Corporate Provider Database contains physician demographic characteristics, training and practice location, defined using the Ontario Medical Association's Rurality Index for Ontario.. Physician group affiliations are identified in the Client Agency Program Enrolment database of patient enrolments with primary care groups. We determined patient demographic characteristics including age, sex, residence and regional health service planning area (Local Health Integration Network) from the Ontario Health Insurance Plan Registered Persons Database. We identified encounters with rheumatologists using the Ontario Health Insurance Plan Claims History Database, with rheumatology specialty defined with the use of the Institute for Clinical Evaluative Sciences Physician Database.

These data sets are linked with the use of unique, encoded patient and physician identifiers and are securely held and analyzed at the Institute for Clinical Evaluative Sciences.

\section{Participants}

At the time of the study, 168 primary care physicians were included in the Electronic Medical Record Administrative data Linked Database. Among 268854 patients with valid health insurance numbers, we identified those who had at least 1 electronic letter of referral to a rheumatologist in the EMR between 2000 and 2013. We obtained administrative data for these patients up until Oct. 31, 2014. In an effort to study only first-time referrals, we excluded patients with rereferrals (occurring if the first referral took place before the EMR start date), second opinions, miscoded referral letters, or missing or invalid referral dates.

\section{Data abstraction}

Using a standardized data abstraction tool, we reviewed the entire EMR to categorize each patient according to the principal diagnosis associated with the referral and to identify the date of symptom onset and the date of the first encounter related to the complaint with the primary care physician. We performed double data abstraction on an initial $10 \%$ sample of charts, whereby the data for each patient were abstracted a second time by the same abstractor and once by a different abstractor. To ensure good agreement, we required $\kappa$ scores for inter- and intrarater reliability to exceed 0.85 before commencing full data abstraction. For all patients, an independent abstractor (J.W.) also performed double data abstraction related to assigning patients to diagnostic categories.

Patients were assigned to 1 of 6 diagnostic categories: osteoarthritis, systemic inflammatory rheumatic diseases, regional musculoskeletal syndromes (e.g., tendinitis), chronic pain conditions (e.g., fibromyalgia), osteoporosis/osteopenia and other (e.g., abnormal test results). Systemic inflammatory rheumatic diseases were further categorized into the following mutually exclusive categories: rheumatoid arthritis, other inflammatory arthritis (e.g., seronegative, undifferentiated, palindromic rheumatism), gout and other forms of crystal arthropathy (e.g., pseudogout, calcium pyrophosphate deposition), psoriatic arthritis, other types of spondyloarthropathy (e.g., ankylosing spondylitis, reactive, enteropathic), polymyalgia rheumatica, vasculitis and other systemic autoimmune rheumatic diseases (e.g., systemic lupus erythematosus, scleroderma, Sjögren syndrome, dermatopolymyositis, Raynaud syndrome). In cases in which several conditions coexisted, the patient was assigned to the most serious complaint requiring consultation (e.g., a patient with preexisting osteoarthritis and acute-onset inflammatory arthritis was categorized into the latter category). When there was discordance between physicians, the diagnosis was 
categorized according to the rheumatologist's impression (based on consultation letters received after referral).

\section{Statistical analysis}

To determine the generalizability of our results, we compared the study physicians with all Ontario primary care physicians in terms of demographic characteristics (sex, age, practice location), medical training location, primary care model and practice duration. We used descriptive statistics to characterize the study population according to reason for referral. The wait time was determined overall and for each diagnostic category for each component of the care pathway: symptom onset until the date of the first primary care visit related to the complaint, first primary care visit related to the complaint until the date of referral to a rheumatologist, and date of referral to the date of the first rheumatologist visit. Patients were followed for at least 365 days from the date of the referral to identify the date of the first rheumatologist visit subsequent to the referral date recorded in the EMR. We compared the observed wait times with the established target wait times to determine the proportion of patients seen by a rheumatologist within each time frame. We estimated actual median (and interquartile range $[\mathrm{IQR}]$ ) wait times (in days) and estimated 50th and 90th percentiles. We estimated wait times from symptom onset for patients with systemic inflammatory conditions for whom symptom onset dates could be determined. We also evaluated regional wait times according to residence.

We analyzed coded data using SAS version 9.2 and Microsoft SQL Server 2012. Ethics approval was obtained from the institutional review board at Sunnybrook Health Sciences Centre, Toronto.

\section{Results}

The study physicians (representing 32 rural, 39 suburban, and 97 urban practices) were slightly younger than all Ontario primary care physicians, with a greater proportion of women and more rural representation (Table 1).

After screening 2925 patients to identify first-time referrals, we excluded 495 patients, as follows: miscoded referral letter, 204 patients; re-referral, 133; possible re-referral, 73; second opinion, 5; and other, 80 . We thus retained the data for 2430 patients $(83.1 \%)$ for analyses. A total of 2417 referrals (99.5\%) occurred between 2005 and 2013, corresponding to the average duration of EMR use.

Of the 2430 patients referred to rheumatologists, 1682 $(69.2 \%)$ were female (Table 2). The mean age at the time of referral was 53.0 (SD 16.3) years. The most frequent diagnoses were osteoarthritis (787 patients [32.4\%]) and systemic inflammatory rheumatic diseases $(745[30.7 \%])$. Of the 745 patients with systemic inflammatory rheumatic diseases, 120 (16.1\%) had rheumatoid arthritis, 167 (22.4\%) had other inflammatory arthritis, 131 (17.6\%) had other systemic autoimmune rheumatic diseases, 122 (16.4\%) had crystal arthropathy, 76 (10.2\%) had spondylitis/spondyloarthropathy, 44 $(5.9 \%)$ had psoriatic arthritis, $66(8.8 \%)$ had polymyalgia rheumatica, and 19 (2.6\%) had vasculitis (Table 2). The other systemic autoimmune rheumatic diseases included primary Raynaud syndrome (33 patients), mixed or undifferentiated connective tissue disease (32), systemic lupus erythematosus (24), scleroderma (10) and other (32).

In total, 68 patients $(2.8 \%)$ had documentation of declining or missing the initial rheumatology consultation after the referral letter was sent (Table 3). Of the 68, 24 (35.3\%) subsequently saw a rheumatologist. A total of 87 referrals (3.6\%) were declined by the first rheumatologist approached to assess the patient; most of the declined referrals were for nonsystemic inflammatory conditions. The most common reason for refusal was that the rheumatologist assessed patients with

\section{Table 1: Comparison of EMRALD study physicians and all primary care physicians in Ontario as of Mar. 31, 2014}

No. $(\%)$ of physicians *

\begin{tabular}{|c|c|c|}
\hline \multirow[b]{2}{*}{ Characteristic } & \multicolumn{2}{|c|}{ No. (\%) of physicians* } \\
\hline & $\begin{array}{c}\text { EMRALD } \\
\text { physicians } \\
n=168\end{array}$ & $\begin{array}{c}\text { All primary care } \\
\text { physicians in } \\
\text { Ontario† } \\
n=8054\end{array}$ \\
\hline \multicolumn{3}{|l|}{ Sex } \\
\hline Female & $94(56.0)$ & $3333(41.4)$ \\
\hline Male & $74(44.0)$ & 4721 (58.6) \\
\hline \multicolumn{3}{|l|}{ Age, yr } \\
\hline$<35$ & $25(14.9)$ & $500(6.2)$ \\
\hline $35-44$ & $57(33.9)$ & $1643(20.4)$ \\
\hline $45-54$ & $36(21.4)$ & $2425(30.1)$ \\
\hline $55-79$ & $46(27.4)$ & $3471(43.1)$ \\
\hline Unknown & $4(2.4)$ & $15(0.2)$ \\
\hline \multicolumn{3}{|l|}{ Medical training location } \\
\hline Canada & $150(89.3)$ & $5967(74.1)$ \\
\hline Elsewhere/unknown & $18(10.7)$ & 2087 (25.9) \\
\hline \multicolumn{3}{|l|}{ Practice location } \\
\hline Rural & $32(19.0)$ & $608(7.5)$ \\
\hline Suburban & $39(23.2)$ & $1313(16.3)$ \\
\hline Urban & $97(57.7)$ & $6133(76.1)$ \\
\hline \multicolumn{3}{|l|}{ Practice model } \\
\hline FHG or FHN & $18(10.7)$ & 2795 (34.7) \\
\hline $\mathrm{FHO}$ & $136(81.0)$ & $3525(43.8)$ \\
\hline Other/unknown & $14(8.3)$ & $1734(21.5)$ \\
\hline Age, yr, mean (range) & $46.6(28-69)$ & $52.2(27-79)$ \\
\hline $\begin{array}{l}\text { Years in practice, mean } \\
\text { (range) }\end{array}$ & $15.2(1-36)$ & $18.5(0-45)$ \\
\hline $\begin{array}{l}\text { Years since graduation, } \\
\text { mean (range) }\end{array}$ & $19.9(3-43)$ & $26.3(2-65)$ \\
\hline \multicolumn{3}{|c|}{$\begin{array}{l}\text { Note: EMRALD = Electronic Medical Record Administrative data Linked } \\
\text { Database, FHG = Family Health Group, FHN = Family Health Network, FHO = } \\
\text { Family Health Organization. } \\
\text { *Unless stated otherwise. } \\
\text { †Primary care physicians whose practice was focused on primary care were } \\
\text { defined as having a main specialty of general practice/family practice or } \\
\text { community medicine/public health. }\end{array}$} \\
\hline
\end{tabular}




\section{OPEN}

certain conditions only (Table 3 ). Of the 87 patients, 51 $(58.6 \%)$ subsequently saw another rheumatologist.

A total of 2015 patients (82.9\%) were seen by 146 rheumatologists within 365 days of referral, and 1414 patients $(58.2 \%)$ were seen within 3 months of referral. Wait times varied by diagnosis (Table 4). The median time (IQR) from the date of referral to the rheumatologist consultation was 74 (27-101) days among all patients and 66 (18-84) days among the patients with systemic inflammatory rheumatic diseases; $242(32.5 \%)$ of the latter were seen within 4 weeks of referral (Table 4). Compared with the benchmark of $100 \%,{ }^{7,8} 46$ patients $(38.3 \%)$ with rheumatoid arthritis were seen within 4 weeks of referral, 59 patients (35.3\%) with other forms of inflammatory arthritis were seen within 4 weeks of referral, 48 patients $(63.2 \%)$ with spondyloarthritis were seen within 3 months of referral, and 15 patients $(34.1 \%)$ with psoriatic arthritis were seen within 6 weeks of referral. For patients with rheumatoid arthritis, the median wait time (IQR) to be seen by a rheumatologist from symptom onset was 327 (83410) days and from date of referral, 66 (15-81) days (Tables 4 and 5). Wait times from symptom onset to rheumatologist consultation also varied among different types of systemic inflammatory rheumatic diseases (Table 5) and for the 3 phases of the care pathway. The total wait was longest for patients with crystal arthropathy and those with spondylitis. The longest waits consistently occurred before referral. For patients with rheumatoid arthritis, the median time (IQR) from symptom onset to referral was 326 (49-375) days.

Geographic variations in wait times were observed (Table 6). The longest wait times occurred in the South West, South East and Champlain Local Health Integration Networks, where median wait times from referral to rheumatology con- sultation were 2-3 times those in the Central East Local Health Integration Network.

\section{Interpretation}

We conducted a data linkage study using EMRs from a representative sample of primary care practices to evaluate the total wait faced by patients to see a rheumatologist, including the time from symptom onset to see a primary care physician, the time from the primary care encounter to referral, and the time from referral to rheumatologist consultation. We observed exceedingly long wait times. Established wait time benchmarks ${ }^{7,8}$ were not achieved for even the most urgent types of referral (i.e., inflammatory arthritis including rheumatoid arthritis). Close to 1 in 3 referrals were for systemic inflammatory conditions, and these patients were seen earlier compared to those referred for other conditions. However, most of the delay for these urgent conditions occurred before referral, representing delays in patients seeking medical attention and family physicians waiting too long to refer patients who required earlier access to specialist care. Increasing patient awareness and medical education are thus acutely needed.

Previous Canadian reports among patients with rheumatoid arthritis seen in urban settings showed shorter wait times than our study: 3 to 6 months from symptom onset to referral (compared with a median of 11 months in our study) and about 1 month from referral to rheumatologist consultation (compared with a median of 74 days in our study). ${ }^{24-26,28,29}$ Our findings confirm that wait times in certain urban areas, such as Toronto, are shorter than elsewhere in the province. There is also ample evidence from international studies supporting our finding that most of the delay occurs before referral. ${ }^{32-36}$ However, the total

\begin{tabular}{|c|c|c|c|}
\hline Diagnosis & No. of patients & $\begin{array}{l}\text { Age, yr, } \\
\text { mean } \pm \text { SD }\end{array}$ & $\begin{array}{l}\text { Female, } \\
\text { no. }(\%)\end{array}$ \\
\hline All patients & 2430 & $53.0 \pm 16.3$ & $1682(69.2)$ \\
\hline Osteoarthritis & 787 & $56.4 \pm 15.6$ & $554(70.4)$ \\
\hline Systemic inflammatory rheumatic disease & 745 & $53.4 \pm 17.0$ & $427(57.3)$ \\
\hline Rheumatoid arthritis & 120 & $55.4 \pm 15.8$ & $84(70.0)$ \\
\hline Inflammatory arthritis, other & 167 & $50.9 \pm 16.2$ & 95 (56.9) \\
\hline Crystal arthropathy & 122 & $61.3 \pm 15.3$ & $33(27.0)$ \\
\hline Spondylitis/spondyloarthropathy & 76 & $41.5 \pm 15.2$ & $31(40.8)$ \\
\hline Psoriatic arthritis & 44 & $52.9 \pm 12.6$ & $26(59.1)$ \\
\hline Polymyalgia rheumatica & 66 & $71.2 \pm 9.2$ & $41(62.1)$ \\
\hline Vasculitis & 19 & $52.7 \pm 23.5$ & $10(52.6)$ \\
\hline $\begin{array}{l}\text { Other systemic autoimmune rheumatic } \\
\text { disease }\end{array}$ & 131 & $45.3 \pm 13.9$ & $107(81.7)$ \\
\hline Regional musculoskeletal syndrome & 395 & $52.2 \pm 15.8$ & $286(72.4)$ \\
\hline Chronic pain condition & 346 & $46.5 \pm 14.3$ & $298(86.1)$ \\
\hline Osteoporosis & 45 & $62.3 \pm 15.2$ & $38(84.4)$ \\
\hline Other & 112 & $46.3 \pm 16.3$ & $79(70.5)$ \\
\hline
\end{tabular}


delay to rheumatology consultation may be substantially longer in Ontario than in other countries. For example, the median delay from symptom onset to rheumatologist consultation for patients with rheumatoid arthritis across 10 European centres was 24 weeks, ${ }^{33}$ compared to 47 weeks (327 days) in our sample. These findings suggest that delays are related in part to the awareness and care-seeking behaviour of patients and that there is opportunity to improve screening in primary care in Ontario.

In Canada, both rheumatologists and primary care physicians identify long wait times as a barrier to providing adequate care, ${ }^{37-39}$ and waits to see rheumatologists are longer than for most other medical subspecialties. ${ }^{40}$ Our findings underline the need to increase awareness among patients, physicians and policy-makers of the major burden that rheumatic diseases places on patients, society and health care systems, and to prioritize planning of health care services, medical education ${ }^{41,42}$ and research. ${ }^{6}$ The relative shortage of rheumatologists, ${ }^{43-45}$ especially in rural areas, and the projected increasing burden of rheumatic diseases ${ }^{1,5}$ suggest a need for innovative models of care. ${ }^{46,47}$ Rheumatology referrals often are not done in a standardized or consistent way,

\section{Table 3: Main reasons for declined referrals}

\begin{tabular}{|lc|}
\hline Reason & $\begin{array}{c}\text { No. (\%) of patients } \\
n=2430\end{array}$ \\
\hline $\begin{array}{l}\text { Patient declined or missed } \\
\text { consultation after first referral sent }\end{array}$ & $68(2.8)$ \\
\hline Symptoms resolved & $6(8.8)$ \\
\hline Patient choice & $21(30.9)$ \\
\hline $\begin{array}{l}\text { Patient unavailable/missed } \\
\text { appointment }\end{array}$ & $26(38.2)$ \\
\hline $\begin{array}{l}\text { Rheumatologist declined } \\
\text { consultation after first referral sent }\end{array}$ & $87(3.6)$ \\
\hline $\begin{array}{l}\text { Consulted only for certain } \\
\text { conditions }\end{array}$ & $23(26.4)$ \\
\hline $\begin{array}{l}\text { Rheumatologist suggested } \\
\text { alternative plan (e.g., pain clinic, } \\
\text { another specialist) }\end{array}$ & $21(24.1)$ \\
\hline No reason provided & $19(21.8)$ \\
\hline Not accepting new patients & $10(11.5)$ \\
\hline
\end{tabular}

Table 4: Wait time from date of referral to rheumatologist consultation

\begin{tabular}{|c|c|c|c|c|c|c|c|c|c|c|}
\hline All patients & 2430 & $579(23.8)$ & $846(34.8)$ & 1414 (58.2) & 1839 (75.7) & $1963(80.8)$ & 2015 (82.9) & $74(27-101)$ & 57 & 170 \\
\hline Osteoarthritis & 787 & $168(21.3)$ & $249(31.6)$ & 454 (57.7) & 601 (76.4) & $640(81.3)$ & $661(84.0)$ & $73(30-103)$ & 62 & 174 \\
\hline Rheumatoid arthritis & 120 & $46(38.3) \dagger$ & $57(47.5)$ & $85(70.8)$ & $95(79.2)$ & $101(84.2)$ & $104(86.7)$ & $66(15-81)$ & 37 & 166 \\
\hline $\begin{array}{l}\text { Inflammatory } \\
\text { arthritis, other }\end{array}$ & 167 & $59(35.3) \dagger$ & $85(50.9)$ & $117(70.1)$ & $133(79.6)$ & 139 (83.2) & $143(85.6)$ & $55(17-71)$ & 38 & 128 \\
\hline Crystal arthropathy & 122 & $33(27.0)$ & $51(41.8)$ & $78(63.9)$ & $101(82.8)$ & 107 (87.7) & 108 (88.5) & $69(24-93)$ & 52 & 156 \\
\hline Vasculitis & 19 & $10(52.6)$ & $12(63.2)$ & $14(73.7)$ & $14(73.7)$ & 15 (78.9) & 15 (78.9) & $28(11-39)$ & 16 & 71 \\
\hline $\begin{array}{l}\text { Other systemic } \\
\text { autoimmune } \\
\text { rheumatic disease }\end{array}$ & 131 & $35(26.7)$ & $53(40.5)$ & $81(61.8)$ & $99(75.6)$ & $103(78.6)$ & $107(81.7)$ & $62(22-83)$ & 46 & 137 \\
\hline $\begin{array}{l}\text { Regional } \\
\text { musculoskeletal } \\
\text { syndrome }\end{array}$ & 395 & $99(25.1)$ & $145(36.7)$ & $240(60.8)$ & $307(77.7)$ & $323(81.8)$ & $330(83.5)$ & $68(26-94)$ & 53 & 152 \\
\hline Chronic pain condition & 346 & $51(14.7)$ & $88(25.4)$ & $161(46.5)$ & $236(68.2)$ & $263(76.0)$ & 271 (78.3) & $90(35-125)$ & 72 & 204 \\
\hline Osteoporosis & 45 & NR $\ddagger$ & NR $\ddagger$ & $9(20.0)$ & $24(53.3)$ & $28(62.2)$ & $28(62.2)$ & $82(74-156)$ & 118 & 183 \\
\hline
\end{tabular}




\section{OPEN}

Research

and wait times vary by rheumatologist. Primary care physicians may refer patients to the rheumatologist they know the best, ${ }^{48}$ unaware of the shorter wait times to access other rheumatologists. This suggests a need for better ways to systematically track and report wait times at the specialist level.

\section{Limitations}

Several limitations warrant discussion. The retrospective nature of the data meant that we were reliant on accurate clinical documentation. This raises the possibility of misclassification between diagnostic categories. Because patients with more classic disease presentation or more active disease may be more correctly diagnosed, and wait times may be different for such patients, such misclassification could introduce bias. Furthermore, dates of symptom onset may be inaccurately documented, and we were unable to estimate this date for all patients. However, dates of symptom onset for systemic inflammatory conditions with acute onset are less likely to be affected by recall bias. Finally, wait times are likely to differ across provinces. Our observed regional variations within province did not appear to correlate well with regional rheu- matology supply, as patients may seek care outside of their health service planning region or there may be different thresholds for referral by geographic region. For example, the delay from symptom onset to rheumatologist consultation for rheumatoid arthritis was much longer in the North East Local Health Integration Network than in other regions, yet the wait from referral to rheumatologist consultation was shorter. This may reflect referrals' being requested when physicians are aware of locum rheumatologists visiting the area.

\section{Conclusion}

We have described a novel approach to monitoring wait times for specialist care in the absence of a national wait time reporting system. Wait times to see a rheumatologist in Ontario exceeded established benchmarks, and improving access is urgently required. For systemic inflammatory rheumatic diseases, most of the delay occurred before referral. Targeted efforts are needed to promote more timely consultations. Because Canadian administrative data currently cannot be used to monitor wait times to see specialists, approaches to linking EMR and administrative data are worth exploring.

Table 5: Median wait time from symptom onset to rheumatologist consultation for systemic inflammatory rheumatic diseases ${ }^{\star}$

\begin{tabular}{|c|c|c|c|c|c|c|c|c|}
\hline Variable & $\begin{array}{l}\text { Rheumatoid } \\
\text { arthritis } \\
n=101\end{array}$ & $\begin{array}{c}\text { Inflammatory } \\
\text { arthritis, other } \\
\quad n=147\end{array}$ & $\begin{array}{c}\text { Crystal } \\
\text { arthropathy } \\
n=97\end{array}$ & $\begin{array}{l}\text { Spondylitis/ } \\
\text { spondylo- } \\
\text { arthropathy } \\
n=56\end{array}$ & $\begin{array}{c}\text { Psoriatic } \\
\text { arthritis } \\
n=35\end{array}$ & $\begin{array}{c}\text { Polymyalgia } \\
\text { rheumatica } \\
n=60\end{array}$ & $\begin{array}{c}\text { Vasculitis } \\
n=18\end{array}$ & $\begin{array}{l}\text { Other systemic } \\
\text { autoimmune } \\
\text { rheumatic } \\
\text { disease } \\
n=96\end{array}$ \\
\hline \multicolumn{9}{|l|}{$\begin{array}{l}\text { Median wait time } \\
\text { (IQR), d }\end{array}$} \\
\hline $\begin{array}{l}\text { Symptom onset to } \\
\text { primary care visit }\end{array}$ & $\begin{array}{c}173 \\
(16-189)\end{array}$ & $\begin{array}{c}102 \\
(10-112)\end{array}$ & $\begin{array}{c}188 \\
(4-192)\end{array}$ & $\begin{array}{c}716 \\
(14-730)\end{array}$ & $\begin{array}{c}228 \\
(17-245)\end{array}$ & $\begin{array}{c}63 \\
(14-77)\end{array}$ & $\begin{array}{c}128 \\
(3-131)\end{array}$ & $\begin{array}{c}208 \\
(14-222)\end{array}$ \\
\hline $\begin{array}{l}\text { Primary care visit } \\
\text { to referral } \ddagger\end{array}$ & $\begin{array}{c}115 \\
(14-128)\end{array}$ & $\begin{array}{c}125 \\
(11-136)\end{array}$ & $\begin{array}{c}353 \\
(20-373)\end{array}$ & $\begin{array}{c}173 \\
(7-181)\end{array}$ & $\begin{array}{c}513 \\
(15-528)\end{array}$ & $\begin{array}{c}123 \\
(15-138)\end{array}$ & $\begin{array}{c}73 \\
(7-80)\end{array}$ & $\begin{array}{c}181 \\
(7-188)\end{array}$ \\
\hline $\begin{array}{l}\text { Symptom onset to } \\
\text { referral }\end{array}$ & $\begin{array}{c}326 \\
(49-375)\end{array}$ & $\begin{array}{c}259 \\
(41-300)\end{array}$ & $\begin{array}{c}1326 \\
(48-1374)\end{array}$ & $\begin{array}{c}1342 \\
(63-1405)\end{array}$ & $\begin{array}{c}627 \\
(90-7167)\end{array}$ & $\begin{array}{c}238 \\
(55-293)\end{array}$ & $\begin{array}{c}293 \\
(33-325)\end{array}$ & $\begin{array}{c}855 \\
(44-899)\end{array}$ \\
\hline $\begin{array}{l}\text { Referral to } \\
\text { rheumatologist } \\
\text { consultation§ }\end{array}$ & $\begin{array}{c}66 \\
(15-81)\end{array}$ & $\begin{array}{c}55 \\
(17-71)\end{array}$ & $\begin{array}{c}69 \\
(24-93)\end{array}$ & $\begin{array}{c}62 \\
(29-91)\end{array}$ & $\begin{array}{c}88 \\
(30-117)\end{array}$ & $\begin{array}{c}53 \\
(11-64)\end{array}$ & $\begin{array}{c}28 \\
(11-39)\end{array}$ & $\begin{array}{c}62 \\
(22-83)\end{array}$ \\
\hline $\begin{array}{l}\text { Symptom onset to } \\
\text { rheumatologist } \\
\text { consultation }\end{array}$ & $\begin{array}{c}327 \\
(83-410)\end{array}$ & $\begin{array}{c}260 \\
(91-350)\end{array}$ & $\begin{array}{c}1312 \\
(111-1423)\end{array}$ & $\begin{array}{c}1262 \\
(112-1374)\end{array}$ & $\begin{array}{c}680 \\
(125-805)\end{array}$ & $\begin{array}{c}240 \\
(81-321)\end{array}$ & $\begin{array}{c}608 \\
(59-667)\end{array}$ & $\begin{array}{c}940 \\
(113-1053)\end{array}$ \\
\hline \multicolumn{9}{|c|}{ No. (\%) of patients seen by rheumatologist within: } \\
\hline $\begin{array}{l}3 \text { mo from } \\
\text { symptom onset }\end{array}$ & $24(24)$ & $31(21)$ & $15(15)$ & $8(14)$ & NRף & $17(28)$ & NRף & $16(17)$ \\
\hline $\begin{array}{l}6 \text { mo from } \\
\text { symptom onset }\end{array}$ & $42(42)$ & $67(46)$ & $34(35)$ & $19(34)$ & $12(34)$ & $32(53)$ & 7 (39) & $29(30)$ \\
\hline $\begin{array}{l}9 \text { mo from } \\
\text { symptom onset }\end{array}$ & $50(50)$ & $86(59)$ & $44(45)$ & $22(39)$ & $15(43)$ & $38(63)$ & $8(44)$ & $40(42)$ \\
\hline $\begin{array}{l}12 \text { mo from } \\
\text { symptom onset }\end{array}$ & $60(59)$ & $97(66)$ & $46(47)$ & $23(41)$ & $17(49)$ & $43(72)$ & $10(56)$ & $45(47)$ \\
\hline \multicolumn{9}{|c|}{$\begin{array}{l}\text { Note: IQR = interquartile range, } N R=\text { not reportable. } \\
\text { *Analyses confined to patients with date of symptom onset captured in their medical record. } \\
\text { tDefined as first documentation of the complaint within the primary care medical record. } \\
\text { fDefined as the date the referral was sent to the rheumatologist. } \\
\text { §Defined as the first visit to the rheumatologist. } \\
\text { TSuppressed to protect privacy. }\end{array}$} \\
\hline
\end{tabular}


Table 6: Median wait time from referral to rheumatologist consultation, by patient's health service planning region (LHIN)

\begin{tabular}{|c|c|c|c|c|c|}
\hline LHIN no. & LHIN & No. $(\%)$ of patients & $\begin{array}{l}\text { Median wait time (IQR), } \\
\text { d }\end{array}$ & $\begin{array}{l}\text { No. of } \\
\text { rheumatologists } \\
\text { in 2009/10 }\end{array}$ & $\begin{array}{c}\text { No. of } \\
\text { rheumatologists } \\
\text { per } 100000\end{array}$ \\
\hline 13 & North East & $190(7.8)$ & $55.0(37.0-92.0)$ & $<6$ & 0.2 \\
\hline 3 & Waterloo Wellington & $405(16.7)$ & $77.5(28.0-105.5)$ & $<6$ & 0.5 \\
\hline 1 & Erie St. Clair & $\mathrm{NR}^{*}$ & $\mathrm{NR}^{*}$ & $<6$ & 0.7 \\
\hline 5 & Central West & $90(3.7)$ & $103.0(41.0-144.0)$ & $<6$ & 0.8 \\
\hline 12 & North Simcoe Muskoka & $224(9.2)$ & $77.5(25.5-103.0)$ & $<6$ & 0.8 \\
\hline 9 & Central East & $184(7.6)$ & 46.3 (32.0-78.3) & 12 & 0.9 \\
\hline 14 & North West & $\mathrm{NR}^{*}$ & $\mathrm{NR}^{*}$ & $<6$ & 1.0 \\
\hline 2 & South West & $182(7.5)$ & $146.5(34.3-180.8)$ & 9 & 1.1 \\
\hline 6 & Mississauga Halton & $29(1.2)$ & $65.0(17.0-82.0)$ & 11 & 1.2 \\
\hline 8 & Central & $365(15.0)$ & $72.3(27.0-99.3)$ & 18 & 1.3 \\
\hline 10 & South East & $13(0.5)$ & $125.2(30.8-156.0)$ & 6 & 1.4 \\
\hline 4 & $\begin{array}{l}\text { Hamilton Niagara } \\
\text { Haldimand Brant }\end{array}$ & $67(2.8)$ & $71.2(24.3-95.5)$ & 19 & 1.6 \\
\hline 11 & Champlain & $166(6.8)$ & $112.2(49.8-162.0)$ & 19 & 1.8 \\
\hline 7 & Toronto Central & 509 (20.9) & $59.0(15.0-74.0)$ & 50 & 5.2 \\
\hline- & All Ontario regions & $2430(100.0)$ & $74.0(27.0-101.0)$ & 162 & 1.5 \\
\hline
\end{tabular}

\section{References}

1. Global Burden of Disease Study 2013 Collaborators. Global, regional and national incidence, prevalence, and years lived with disability for 301 acute and chronic diseases and injuries in 188 countries, 1990-2013: a systematic analysis for the Global Burden of Disease Study 2013. Lancet 2015;386:743-800.

2. GBD 2013 Mortality and Causes of Death Collaborators. Global, regional, and national age-sex specific all-cause and cause-specific mortality for 240 causes of death, 1990-2013: a systematic analysis for the Global Burden of Disease Study 2013. Lancet 2015;385:117-71.

3. Verschueren P, Westhovens R. Optimal care for early RA patients: the challenge of translating scientific data into clinical practice. Rheumatology (Oxford) 2011;50:1194-200.

4. Hoy DG, Smith E, Cross M, et al. Reflecting on the global burden of musculoskeletal conditions: lessons learnt from the global burden of disease 2010 study and the next steps forward. Ann Rheum Dis 2015;74:4-7.

5. Smith E, Hoy DG, Cross M, et al. The global burden of other musculoskeletal disorders: estimates from the Global Burden of Disease 2010 study. Ann Rheum Dis 2014;73:1462-9.

6. Al Maini M, Adelowo F, Al Saleh J, et al. The global challenges and opportunities in the practice of rheumatology: white paper by the World Forum on Rheumatic and Musculoskeletal Diseases. Clin Rheumatol 2015;34:819-29.

7. Time to close the gap: report card on wait times in Canada. Wait Time Alliance; 2014. Available: www.waittimealliance.ca/wp-content/uploads/2014/06/ FINAL-EN-WTA-Report-Card.pdf (accessed 2015 Nov. 1).

8. Barber CE, Marshall DA, Mosher DP, et al. Development of system-level performance measures for evaluation of models of care for inflammatory arthritis in Canada. F Rheumatol 2016;43:530-40.

9. Wait-time benchmarks for rheumatology. Canadian Rheumatology Association; 2015. Available: www.waittimealliance.ca/wp-content/uploads/2014/05/ Wait-Time-Benchmarks-for-Rheumatology-FINAL.pdf (accessed 2015 Nov. 1).

10. Bosello S, Fedele AL, Peluso G, et al. Very early rheumatoid arthritis is the major predictor of major outcomes: clinical ACR remission and radiographic non-progression. Ann Rheum Dis 2011;70:1292-5.

11. Jayakumar K, Norton S, Dixey J, et al. Sustained clinical remission in rheumatoid arthritis: prevalence and prognostic factors in an inception cohort of patients treated with conventional DMARDS. Rheumatology 2012;51:169-75.

12. van der Woude D, Young A, Jayakumar K, et al. Prevalence of and predictive factors for sustained disease-modifying antirheumatic drug-free remission in rheumatoid arthritis: results from two large early arthritis cohorts. Arthritis Rheum 2009;60:2262-71.
13. Finckh A, Liang MH, van Herckenrode CM, et al. Long-term impact of early treatment on radiographic progression in rheumatoid arthritis: a meta-analysis. Arthritis Rheum 2006;55:864-72.

14. Anderson JJ, Wells G, Verhoeven AC, et al. Factors predicting response to treatment in rheumatoid arthritis: the importance of disease duration. Arthritis Rheum 2000;43:22-9.

15. Nell VP, Machold KP, Eberl G, et al. Benefit of very early referral and very early therapy with disease-modifying anti-rheumatic drugs in patients with early rheumatoid arthritis. Rheumatology (Oxford) 2004;43:906-14.

16. van der Linden MP, le Cessie S, Raza K, et al. Long-term impact of delay in assessment of patients with early arthritis. Arthritis Rheum 2010;62:3537-46.

17. Kirkham B, Li W, Boggs R, et al. Early treatment of psoriatic arthritis is associated with improved outcomes: findings from the Etanercept (Enbrel) PRESTA Trial. Arthritis Rheum 2011;63(Suppl 10):1288.

18. Wallace CA, Giannini EH, Spalding SJ, et al. Trial of early aggressive therapy in polyarticular juvenile idiopathic arthritis. Arthritis Rheum 2012;64:2012-21.

19. Barkham N, Keen HI, Coates LC, et al. Clinical and imaging efficacy of infliximab in HLA-B27-positive patients with magnetic resonance imaging-determined early sacroiliitis. Arthritis Rheum 2009;60:946-54.

20. Haibel H, Rudwaleit M, Listing J, et al. Efficacy of adalimumab in the treatment of axial spondylarthritis without radiographically defined sacroiliitis: results of a twelve-week randomized, double-blind, placebo-controlled trial followed by an open-label extension up to week fifty-two. Arthritis Rheum 2008; 58:1981-91.

21. Wallis D, Inman RD. Recognition of preclinical and early disease in axial spondyloarthritis. Rheum Dis Clin North Am 2014;40:685-97.

22. Fiehn C, Hajjar Y, Mueller K, et al. Improved clinical outcome of lupus nephritis during the past decade: importance of early diagnosis and treatment Ann Rheum Dis 2003;62:435-9.

23. Haroon M, Gallagher P, FitzGerald O. Diagnostic delay of more than 6 months contributes to poor radiographic and functional outcome in psoriatic arthritis. Ann Rheum Dis 2015;74:1045-50.

24. Jamal S, Alibhai SM, Badley EM, et al. Time to treatment for new patients with rheumatoid arthritis in a major metropolitan city. 7 Rheumatol 2011;38: 1282-8.

25. Feldman DE, Schieir O, Montcalm AJ, et al.; McGill Early Inflammatory Arthritis Research Group. Rapidity of rheumatology consultation for people in an early inflammatory arthritis cohort. Ann Rheum Dis 2009;68:1790-1.

26. Qian J, Ehrmann Feldman D, Bissonauth A, et al. A retrospective review of rheumatology referral wait times within a health centre in Quebec, Canada. Rheumatol Int 2010;30:705-7. 
27. Delaurier A, Bernatsky S, Baron M, et al. Wait times for rheumatology consultation: Is rheumatoid arthritis prioritized? 7 Clin Rheumatol 2012;18:341-4.

28. Tavares R, Pope JE, Tremblay JL, et al. Time to disease-modifying antirheumatic drug treatment in rheumatoid arthritis and its predictors: a national, multicenter, retrospective cohort. 7 Rheumatol 2012;39:2088-97.

29. Nanji JA, Choi M, Ferrari R, et al. Time to consultation and disease-modifying antirheumatic drug treatment of patients with rheumatoid arthritis - northern Alberta perspective. 7 Rheumatol 2012;39:707-11.

30. Tu K, Mitiku TF, Ivers NM, et al. Evaluation of Electronic Medical Record Administrative data Linked Database (EMRALD). Am 7 Manag Care 2014;20: e15-21.

31. Kralj B. Measuring "rurality" for purposes of health-care planning: an empirical measure for Ontario. Ont Med Rev 2000;67:33-52.

32. Kumar K, Daley E, Carruthers DM, et al. Delay in presentation to primary care physicians is the main reason why patients with rheumatoid arthritis are seen late by rheumatologists. Rheumatology (Oxford) 2007;46:1438-40.

33. Raza K, Stack R, Kumar K, et al. Delays in assessment of patients with rheumatoid arthritis: variations across Europe. Ann Rheum Dis 2011;70:1822-5.

34. Stack RJ, Shaw K, Mallen C, et al. Delays in help seeking at the onset of the symptoms of rheumatoid arthritis: a systematic synthesis of qualitative literature. Ann Rheum Dis 2012;71:493-7.

35. Kumar K, Daley E, Khattak F, et al. The influence of ethnicity on the extent of, and reasons underlying, delay in general practitioner consultation in patients with RA. Rheumatology (Oxford) 2010;49:1005-12.

36. Kiely P, Williams R, Walsh D, et al. Contemporary patterns of care and disease activity outcome in early rheumatoid arthritis: the ERAN cohort. Rheumatology (Oxford) 2009;48:57-60.

37. Shipton D, Badley EM, Bookman AA, et al. Barriers to providing adequate rheumatology care: implications from a survey of rheumatologists in Ontario, Canada. 7 Rheumatol 2002;29:2420-5.

38. Glazier RH, Dalby D, Badley E, et al. Management of the early and late presentations of rheumatoid arthritis: a survey of Ontario primary care physicians. CMAF 1996;155:679-87.

39. Bernatsky S, Feldman D, De Civita M, et al. Optimal care for rheumatoid arthritis: a focus group study. Clin Rheumatol 2010;29:645-57.

40. Jaakkimainen L, Glazier R, Barnsley J, et al. Waiting to see the specialist: patient and provider characteristics of wait times from primary to specialty care. BMC Fam Pract 2014;15:16.

41. Freedman KB, Bernstein J. Educational deficiencies in musculoskeletal medicine. 7 Bone foint Surg Am 2002;84-A:604-8.

42. Thompson AE. Improving undergraduate musculoskeletal education: a continuing challenge. 7 Rheumatol 2008;35:2298-9.

43. Widdifield J, Paterson JM, Bernatsky S, et al. The rising burden of rheumatoid arthritis surpasses rheumatology supply in Ontario. Can 7 Public Health 2013; 104:e450-5.

44. Hanly JG; Canadian Council of Academic Rheumatologists. Manpower in Canadian academic rheumatology units: current status and future trends. $\mathcal{F}$ Rheumatol 2001;28:1944-51.

45. Kur J, Koehler B. Rheumatologist demographics in British Columbia: a looming crisis. BCM7 2011;53:128-31.

46. Ahluwalia V, Frank C, Mosher DP, et al. A pan-Canadian approach to inflammatory arthritis models of care. Toronto: Arthritis Alliance of Canada; 2014. Available: www.arthritisalliance.ca/images/PDF/eng/20140430-2030-IAMOCFINAL.pdf (accessed 2015 Nov. 1).

47. Inflammatory arthritis care path toolkit. Toronto: Arthritis Alliance of Canada; 2014. Available: www.arthritisalliance.ca/images/caremap/en/index.htm (accessed 2015 Nov. 1).

48. Lou B, Civita M, Feldman D, et al. Care partnerships between family physicians and rheumatologists. 7 Rheumatol 2011;38:1981-5.

Competing interests: J. Carter Thorne received grants and/or honoraria from Amgen Canada, Pfizer Canada Inc., AbbVie Corporation, BristolMyers Squibb Canada, Centocor, Inc., Merck \& Co., Inc., F. HoffmannLa Roche Ltd. and UCB Canada Inc. outside the submitted work.
Vandana Ahluwalia received grants and consulting fees from AbbVie Corporation, Janssen Canada, Roche Canada, UCB Canada Inc. and Bristol-Myers Squibb Canada, and consulting fees from Amgen Canada/ Wyeth Pharmaceuticals, Pfizer Canada Inc. and Hospira during the conduct of the study.

Affiliations: Department of Clinical Epidemiology (Widdifield, Bernatsky), McGill University Health Centre, Montréal, Que.; Department of Epidemiology, Biostatistics and Occupational Health (Widdifield, Bernatsky), McGill University, Montréal, Que.; Department of Rheumatology (Thorne), Southlake Regional Health Centre, Newmarket, Ont.; Departments of Family and Community Medicine (Jakkimainen, Ivers, Butt, Tu) and Rheumatology (Bombardier), University of Toronto, Toronto, Ont.; Department of Family Medicine (Paterson), McMaster University, Hamilton, Ont.; Department of Family and Community Medicine (Ivers), Women's College Hospital, Toronto, Ont.; Department of Family Medicine (Butt), Scarborough Hospital, Toronto, Ont.; Patient representative (Lyddiatt), Ingersoll, Ont.; Patient representative (Hofstetter), Toronto, Ont.; Department of Rheumatology (Ahluwalia), William Osler Health Centre, Brampton, Ont.

Contributors: Jessica Widdifield, Laura Wing, Karen Tu and Liisa Jaakkimainen had full access to all study data and guarantee the integrity of the data and accuracy of the analyses. Jessica Widdifield drafted the manuscript. All of the authors revised the manuscript critically for important intellectual content, contributed substantially to study design and data analysis and interpretation, gave final approval of the version to be published and agreed to act as guarantors of the work.

Funding: This study was funded by an operating grant from the Canadian Initiative for Outcomes in Rheumatology Care. Jessica Widdifield holds Fellowship Awards from The Arthritis Society and the Canadian Institutes of Health Research (CIHR) (Banting) and is supported by the Canadian Network for Advanced Interdisciplinary Methods for comparative effectiveness research team funded by the CIHR Drug Safety and Effectiveness Network. Sasha Bernatsky holds a Career Award from the Fonds de la recherche en santé du Québec. Claire Bombardier holds a Canada Research Chair in Knowledge Transfer for Musculoskeletal Care and a Pfizer Research Chair in Rheumatology. Noah Ivers is supported by New Investigator Awards from the CIHR and the Department of Family and Community Medicine, University of Toronto. Karen Tu, R. Liisa Jaakkimainen and Debra Butt are supported by Investigator Awards from the Department of Family and Community Medicine, University of Toronto.

ICES disclaimer: This study was supported by the Institute for Clinical Evaluative Sciences (ICES), which is funded by an annual grant from the Ontario Ministry of Health and Long-Term Care (MOHLTC). The opinions, results and conclusions reported in this article are those of the authors and are independent from the funding sources. No endorsement by ICES or the Ontario MOHLTC is intended or should be inferred.

Acknowledgements: The authors thank all the family physicians who provide data to the Electronic Medical Record Administrative data Linked Database. They also thank our chart abstractors for their work: Monique Kerr-Taylor, Adenieki Mornan and Anne Marie Mior.

Supplemental information: For reviewer comments and the original submission of this manuscript, please see www.cmajopen.ca/content/4/2/ E205/suppl/DC1 